\title{
KESEJAHTERAAN KELUARGA PADA IBU YANG BEKERJA SEBAGAI PERAWAT
}

\author{
Arni Nur Rahmawati ${ }^{1}$ \\ ${ }^{1}$ Program Studi S1 Keperawatan Universitas Harapan Bangsa Purwokerto \\ Email: arninr@uhb.ac.id
}

\begin{abstract}
ABSTRAK
Perkembangan zaman dan teknologi yang semakin modern, mendorong seorang ibu untuk bekerja karena alasan finansial, aktualisasi diri, dan relasi. Hal ini menjadikan pekerja wanita terutama ibu bekerja sebagai kelompok rentan dan berisiko terhadap hazard kesehatan pekerjaan. Salah satunya adalah ketidakseimbangan peran antara di pekerjaan dan keluarga akibat peran ganda. Hal ini dapat membuat ibu bekerja menjadi stress sehingga akan mempengaruhi kondisi kesejahteraan ibu bekerja di dalam keluarga. Tujuan penelitian ini adalah untuk mengetahui gambaran kesejahteraan keluarga pada ibu yang bekerja sebagai perawat. Desain yang digunakan dalam penelitian ini adalah deskriptif kuantitatif dengan 52 responden yang merupakan hasil screening berdasarkan kriteria inklusi. Data kesejahteraan keluarga dianalisis menggunakan analisis deskriptif. Hasil penelitian ini menunjukkan nilai rata-rata kesejahteraan keluarga pada ibu yang bekerja sebagai perawat adalah 123,33 dengan komponen kesejahteraan keluarga yang paling dominan adalah kelebihan peran sebesar 81,02\%. Komponen kesejahteraan keluarga terdiri dari kesatuan sistem keluarga meliputi hubungan struktur keluarga; keterkaitan fungsi atau peran dalam melakukan tugas di keluarga; dan mencegah kerentanan keluarga terhadap pengaruh lain seperti genetik, fisiologis, sosiologis, atau psikologis. Berdasarkan hasil tersebut, dapat disimpulkan bahwa kesejahteraan keluarga dapat menggambarkan kemampuan ibu bekerja dalam beradaptasi dengan peran gandanya.
\end{abstract}

Kata kunci : : Ibu bekerja, kesejahteraan keluarga

\begin{abstract}
The times and increasingly modern technology, encourage a mother to work for financial reasons, self-actualization, and relationships. This makes women workers especially mothers work as vulnerable groups and at risk of occupational health hazards. One of them is the role imbalance between work and family due to multiple roles. This can make the mother work stressful so that it will affect the well-being condition of the mother working in the family. The purpose of this study was to describe the family well-being of mothers who worked as nurses. The design used in this study was descriptive quantitative with 52 respondents who were the results of screening based on inclusion criteria. Family well-being data were analyzed using descriptive analysis. The results of this study indicate the average value of family well-being in mothers who work as nurses is 123.33 with the most dominant of family well-being component is the multiple roles of $81,02 \%$. The family well-being component consists of the unity of the family system including the relationship of family structure; the relevance of functions or roles in carrying out tasks in the family; and prevent family vulnerability to other influences such as genetic, physiological, sociological or psychological. Based on these results, it can be concluded that family well-being can describe the ability of the mother to work in adapting to her dual role.
\end{abstract}

Keyword : working mother, family well-being

Viua Medika | VOLUME 11/NOMOR 02/MARET/2019 


\section{PENDAHULUAN}

Perkembangan zaman dan teknologi yang semakin maju di zaman modern ini, menuntut para keluarga untuk dapat bekerja keras memenuhi kebutuhan hidup yang semakin meningkat. Peningkatan kebutuhan keluarga tersebut menyebabkan saat ini tidak hanya ayah yang bekerja tetapi juga mendorong ibu untuk bekerja (Oktaviana, 2015). Jumlah pekerja wanita yang memiliki anak berusia di bawah enam tahun menurut Bureau of Labor Statistics U.S. pada tahun 2010 sejumlah 39\% meningkat menjadi 64\% pada tahun 2011 (Buehler \& Brien, 2011). Di Indonesia, jumlah angkatan kerja pada tahun 2013 sebesar 120,17 juta orang meningkat menjadi 125,44 juta orang pada tahun 2016 (Kemenkes (Kementerian Kesehatan RI), 2016). Sedangkan jumlah pekerja wanita di Jawa Tengah pada tahun 2015 sebesar 6.709.835 orang, meningkat menjadi 6.808.569 orang pada tahun 2016 (Survey Angkatan Kerja Nasional (Sakernas), 2016).
Alasan ibu bekerja karena adanya kebutuhan finansial, kebutuhan sosial relasional, dan kebutuhan aktualisasi diri (Badan Pusat Statistik, 2016). Salah satu pekerjaan seorang ibu adalah perawat. Perawat merupakan profesi yang paling banyak didominasi oleh wanita, dimana wanita merupakan $80 \%$ dari total angkatan kerja di dunia (Sharma, Dhar, \& Tyagi, 2015).

Ibu bekerja merupakan kelompok yang rentan dan berisiko terhadap hazard pekerjaan. Hazard pekerjaan terdiri dari hazard fisik, kimia, biologi, ergonomi, dan psikososial (Nies \& Mcewen, 2014; Oakley, 2008). Adapun hazard pekerjaan perawat yang paling umum dialami adalah hazard ergonomi, diikuti hazard psikososial, biologi, dan kimia (Alavi, 2014; Oakley, 2008; Sabra \& Morsy, 2016).

Salah satu hazard yang sering dialami oleh ibu bekerja adalah hazard psikososial. Hazard psikososial dapat terjadi karena kelebihan beban kerja dan stress sehingga akan menyebabkan burnout dan kelelahan (Alavi, 2014). Hazard psikososial lain yang dialami ibu yang bekerja sebagai perawat 
adalah ketidakseimbangan antara pekerjaan dan keluarga (work family conflict) karena adanya peran ganda. Hasil review oleh Gonnelli dan Raffagnino (2017) menunjukkan bahwa work-family conflict adalah stressor di keperawatan dan merupakan faktor resiko yang paling banyak dianalisis di tempat kerja (Gonnelli, 2017).

Berdasarkan hasil studi pendahuluan kepada 12 orang perawat wanita yang sudah berkeluarga di RS Telogorejo Semarang pada tanggal 15-17 Januari 2018, didapatkan data $75 \%$ ibu yang bekerja sebagai perawat merasa kesulitan dalam menjalankan peran sebagai ibu, merasa tidak mampu memenuhi harapan keluarga terhadap perannya, merasa kemampuannya masih di bawah rekan kerja yang lain, merasa sulit menetapkan tujuan hidup, merasa tidak memiliki makna di setiap kegiatan. Sedangkan sejumlah 25\% ibu yang bekerja sebagai perawat merasa cukup mampu menjalani pekerjaan dengan senang hati, merasa mampu menjalankan tugas sesuai peran orang tua, dan masih berusaha mengembangkan potensi diri dengan tanggung jawab peran yang berlebihan.

Kesejahteraan keluarga ibu bekerja menjadi berkurang dikarenakan ibu bekerja mengalami stress akibat konflik peran ganda dan beban kerja berlebihan (Keorekile, 2015; Sabra \& Morsy, 2016). Hal ini ditandai dengan rasa bersalah, meningkatnya stress, ketidakpuasan ibu pada dirinya sendiri, dan menurunnya performa ibu di pekerjaan dan keluarga. Pernyataan tersebut didukung dengan hasil penelitian bahwa wanita bekerja cenderung mengalami stress lebih tinggi dibandingkan dengan pria karena konflik peran ganda (Widyasrini, 2016). Stress pada ibu bekerja ini akan mempengaruhi kemampuan ibu pada fungsinya dalam pengasuhan anak. Semakin tinggi stress akibat peran ganda, maka fungsi pengasuhan anak pada ibu bekerja akan menurun (Gani, 2016). Didukung pula oleh penelitian Judith L tahun 2015 yang menunjukkan tingginya konflik antara kerja dan keluarga dapat menyebabkan rendahnya kepuasan perkawinan disertai tingkat kesejahteraan keluarga yang rendah (Fischer et al., 2015). 
Kesejahteraan merupakan elemen utama dalam kesehatan mental (Bolier et al., 2014). Kesejahteraan keluarga pada ibu bekerja merupakan kesejahteraan orang tua yang menunjukkan kondisi kesehatan mental dalam membentuk kesatuan sistem keluarga meliputi hubungan struktur keluarga; keterkaitan fungsi atau peran dalam melakukan tugas di keluarga; dan mencegah kerentanan keluarga terhadap pengaruh lain seperti genetik, fisiologis, sosiologis, atau psikologis.

Kesejahteraan keluarga pada ibu bekerja dapat menggambarkan kemampuan ibu dalam mengatasi stressor yang dialami terutama saat berinteraksi dengan suami dan anak (Ora L. Strickland, 2001), sehingga strategi koping dan perilaku yang adaptif dibutuhkan untuk meningkatkan kemampuan seseorang untuk mencapai kesejahteraan di dalam keluarganya (Zheng, Kashi, Fan, Molineux, \& Ee, 2016). Penelitian ini bertujuan untuk mengetahui gambaran kesejahteraan keluarga pada ibu yang bekerja sebagai perawat.

\section{METODOLOGI}

Desain penelitin ini adalah deskriptif kuantitatif (Sugiyono, 2011). Populasi dalam penelitian ini adalah 155 perawat wanita di ruang rawat inap Bugenvile RS Telogorejo Semarang. Sedangkan jumlah sampel yang didapat dari hasil rumus Lameshow adalah sejumlah 52 perawat wanita. Teknik pengambilan sampel menggunakan purposive sampling dengan kriteria inklusi antara lain: perawat wanita yang sudah menikah, berusia 20-40 tahun, bekerja lebih dari 1 tahun, serta tinggal bersama anak dan suami (Saryono, 2011; Sugiyono, 2013).

Penelitian ini dilaksanakan di RS Telogorejo Semarang pada bulan Februari-Mei 2018 dengan alokasi pengambilan data pada bulan AprilMei 2018. Instrumen yang digunakan pada penelitian ini adalah kuesioner Family Well-Being Assessment (FWA) yang dikembangkan oleh Shirley M. Caldwell yang terdiri dari kuesioner kesejahteraan orang tua dan kesejahteraan anak. Pada penelitian ini menggunakan kuesioner FWA terjemahan berbahasa Indonesia yang sudah digunakan peneliti sebelumnya dan sudah diuji nilai validitas dan 
reliabilitasnya. Dari 57 pernyataan yang diuji, 42 item valid dengan $r$ hitung > 0,297 dan 15 item yang tidak valid tidak digunakan dalam penelitian ini. Sedangkan hasil uji reliabilitas dari 42 item yang valid menunjukkan nilai alfa 0,943 (alpha cronbach > 0,600$)$ sehingga instrumen ini reliabel dan dapat digunakan. Data yang didapatkan dianalisis dengan analisis statistik deskriptif.

\section{HASIL DAN PEMBAHASAN}

Data tentang kesejahteraan keluarga pada ibu yang bekerja sebagai perawat dianalisis menggunakan statistik deskriptif.

Tabel 1. Nilai Kesejahteraan Keluarga pada Ibu yang Bekerja sebagai Perawat di RS Telogorejo Bulan April-Mei 2018 (n=52)

\begin{tabular}{lccl}
\hline Variabel & Mean & $\begin{array}{c}\text { Media } \\
\mathbf{n}\end{array}$ & Modus \\
\hline $\begin{array}{l}\text { Kesejahteraa } \\
\text { n keluarga }\end{array}$ & 123,33 & 128 & 128 \\
\hline
\end{tabular}

Tabel 1 menunjukkan rata-rata nilai kesejahteraan keluarga pada ibu yang bekerja sebagai perawat adalah sebesar 123,33.

\section{Tabel 2. Komponen Kesejahteraan} Keluarga pada Ibu yang Bekerja sebagai Perawat di RS Telogorejo Bulan April-Mei 2018 (n=52)

\begin{tabular}{llr}
\hline No & \multicolumn{1}{c}{ Sub Variabel } & \multicolumn{1}{c}{$\begin{array}{c}\text { Prosentase } \\
(\boldsymbol{\%})\end{array}$} \\
\hline 1 & Stress keluarga & 73,08 \\
\hline 2 & Kepuasan keluarga & 79,31 \\
\hline 3 & Dukungan keluarga & 75,67 \\
\hline 4 & Kelebihan peran/multi peran & 81,02 \\
\hline 5 & Adaptasi keluarga & 73,42 \\
\hline 6 & Konflik keluarga & 67,67 \\
\hline 7 & Kekuatan keluarga & 71,5 \\
\hline 8 & Kebingungan peran & 75,66 \\
\hline 9 & Peran tidak berpartisipasi & 71,53 \\
\hline 10 & Ketidaksiapan peran & 65,4 \\
\hline 11 & Kerentanan keluarga & 71,18 \\
\hline & Berdasarkan tabel & diketahui
\end{tabular}

bahwa komponen kesejahteraan keluarga yang paling dominan dan berpengaruh terhadap nilai kesejahteraan keluarga pada ibu yang bekerja sebagai perawat adalah kelebihan peran sebesar 81,02\% akibat adanya peran ganda ibu bekerja antara pekerjaan dan keluarga.

Hasil penelitian ini menunjukkan data rata-rata nilai kesejahteraan keluarga pada ibu yang bekerja sebagai perawat sebesar 123,33. Hal ini menunjukkan bahwa ibu merasa terbebani dengan tanggung jawab keluarga, merasa memiliki tanggung jawab berlebih baik di pekerjaan maupun di keluarga, kesulitan mengatur diri dalam menjalankan

Viua Medika | VOLUME 11/NOMOR 02/MARET/2019 
peran saat di rumah, keluarga terlalu banyak berharap ibu dapat menjalankan perannya dengan baik, dan merasa memiliki harapan tinggi terhadap pelaksanaan perannya di rumah tetapi sulit untuk melaksanakan tugas sesuai peran di keluarga.

Kesejahteraan keluarga pada ibu bekerja merupakan kesejahteraan orang tua yang menggambarkan kondisi kesehatan mental sebagai pondasi kesehatan keluarga. Kesejahteraan ibu bekerja pada penelitian ini didominasi oleh komponen kelebihan peran sebesar $81,02 \%$ akibat peran ganda yang dialami ibu bekerja. Kelebihan peran di sini menunjukkan adanya tanggung jawab pelaksanaan tugas sesuai peran sebagai ibu yang berlebihan yaitu di tempat kerja (sebagai pekerja) dan di rumah (sebagai istri dan ibu). Adapun beberapa faktor yang dapat mempengaruhi kondisi kesejahteraan ibu bekerja di dalam keluarga antara lain usia, pekerjaan, penghasilan, perhatian, penerimaan, adaptasi, dan kesehatan (Across, Centre, \& Centre,
2014; Huppert, 2014; Milnes, 2016; Ryff, 2014).

Seorang ibu memiliki peran yang penting dalam keluarga yaitu pada suami dan anaknya, begitu pun dengan ibu bekerja. Ibu bekerja merupakan seorang ibu yang mampu menggabungkan tanggung jawab antara pekerjaan dan keluarga. Adapun peran ibu bekerja di rumah antara lain sebagai seorang istri, pengurus rumah tangga, pengasuh dan pendidik anak-anaknya, sebagai anggota masyarakat, serta sebagai pencari nafkah tambahan bagi keluarga (Kaakinen,Joanna Rowe;Coehlo,Deborah Padgett; Steele, 2018). Peran ini dapat terlaksana dengan baik jika seorang ibu yang bekerja memiliki koping adaptif terhadap masalah peran ganda yang dialami (Davison, G. C., Neale, J. M., \& King, A., 2010).

Koping positif terdiri dari koping fokus emosi (kondisi emosi internal individu), koping fokus pada tubuh, dan koping fokus masalah (menghadapi stressor dengan aksi langsung). Ibu bekerja di dalam keluarga yang dalam hal ini bekerja 
sebagai perawat, dapat menggunakan koping positif supaya aspek psikologis dapat berfungsi dengan baik dan dapat melakukan kegiatan sehari-hari untuk meningkatkan kesejahteraan (Davison, G. C., Neale, J. M., \& King, A., 2010; Dwidiyanti, Meidiana; Pamungkas, Yanuar F; Ningsih, 2017).

Kesejahteraan keluarga yang tinggi pada ibu bekerja akan berpengaruh terhadap tiga domain penting pada kehidupan seseorang yaitu pekerjaan, hubungan, dan kesehatan (Robertson, Ivan; Cooper, 2011). Berdasarkan hasil penelitian ini, kesejahteraan keluarga akan menguatkan komitmen dan penampilan kerja seorang ibu. Ibu yang bekerja sebagai perawat, mampu memenuhi tingginya permintaan pekerjaan baik antara fisik dan emosi. Selain itu, ibu dapat melakukan peran gandanya sebagai ibu dan wanita karier (Lian \& Tam, 2017; Ora et al., 2016).

\section{KESIMPULAN DAN SARAN}

Hasil penelitian menunjukkan rata-rata nilai kesejahteraan keluarga pada ibu yang bekerja sebagai perawat adalah 123,33. Komponen kesejahteraan keluarga terdiri dari kesatuan sistem keluarga meliputi hubungan struktur keluarga; keterkaitan fungsi atau peran dalam melakukan tugas di keluarga; dan mencegah kerentanan keluarga terhadap pengaruh lain seperti genetik, fisiologis, sosiologis, atau psikologis. Komponen kesejahteraan keluarga yang paling dominan dan berpengaruh terhadap nilai kesejahteraan keluarga pada ibu yang bekerja sebagai perawat adalah kelebihan peran sebesar 81,02\% akibat adanya peran ganda ibu bekerja antara pekerjaan dan keluarga. Berdasarkan hasil tersebut, dapat disimpulkan bahwa kesejahteraan keluarga dapat menggambarkan kemampuan ibu bekerja dalam beradaptasi dengan peran gandanya.

Hasil penelitian ini dapat dijadikan evidence based practice dalam pengembangan intervensi keperawatan terutama dalam bidang keperawatan komunitas kesehatan kerja. Penelitian ini dapat Viua Medika | VOLUME 11/NOMOR 02/MARET/2019 
dikembangkan dengan desain penelitian berbeda dan metode pelaksanaan intervensi yang dimodifikasi sehingga memperkaya ilmu keperawatan terkait intervensi untuk meningkatkan kesejahteraan keluarga pada ibu bekerja.

\section{DAFTAR PUSTAKA}

Across, W., Centre, W. W., \& Centre, T. (2014). What Works To Improve Wellbeing?, 1-8.

Alavi, N. M. (2014). Occupational Hazards in Nursing. Nurs Midwifery Stud, 3(3), 5-6.

Badan Pusat Statistik. (2016). Penempatan Tenaga Kerja.

Bolier, L., Ketelaar, S. M., Nieuwenhuijsen, K., Smeets, O., Gärtner, F. R., \& Sluiter, J. K. (2014). Workplace mental health promotion online to enhance well-being of nurses and allied health professionals: A clusterrandomized controlled trial. INVENT, 1(4), 196-204. https://doi.org/10.1016/j.invent.2 014.10.002

Buehler, C., \& Brien, M. O. (2011). Mothers'

Part-Time Employment : Associations With Mother and Family Well-Being, 25(6).

Davison, G. C., Neale, J. M., \& King, A., M. (2010). Psikologi
Abnormal. (diterjemahkan oleh Noermalasari Fajar, Ed.) (edisi ke-9). Jakarta: Raja Garfindo Persada.

Dwidiyanti, Meidiana; Pamungkas, Yanuar F; Ningsih, H. E. W. (2017). Mindfulness Caring pada Stress. Semarang: UNDIP PRESS.

Erdilek, M., Akyüz, B., \& Elçi, M. (2016). Effects of Family-Work Conflict, Locus of Control, Self Confidence and Extraversion Personality on Employee Work Stress. Procedia - Social and Behavioral Sciences, 235(10), 269-280.

https://doi.org/10.1016/j.sbspro.2 016.11.030

Fischer, J. L., Zvonkovic, A., Juergens, C., Engler, R., \& Frederick, H. (2015). Work, Family, and Well-Being at Midlife: A Person-Centered Approach.

https://doi.org/10.1177/0192513

X13488370

Gani, M. . (2016). Hubungan stres kerja dengan fungsi ibu dalam pengasuhan pada karyawati skripsi. Universitas Muhammadiyah Malang.

Gonnelli, C. (2017). Work-Family Conflict in Nursing: An Integrative Review of Its Antecedents and Outcomes, 3(1), 61-84.

Huppert, F. A. (2014). The state of 
well-being science: concepts, measures, interventions and policies. In: F.A. Huppert and C.L. Cooper (Eds.) Interventions and Policies to Enhance WellBeing. Oxford: Wiley-Blackwell.

Kaakinen,Joanna

Rowe;Coehlo,Deborah Padgett; Steele, R. (2018). Family Health Care Nursing: Theory, Practice, and Research (sixth edit). Philadelphia: Davis Company.

Kemenkes (Kementerian Kesehatan RI). (2016). Profil Kesehatan Indonesia 2015.

Keorekile, O. (2015). Occupational health hazards encountered by nurses at Letsholathebe II Memorial Hospital in Maun, Botswana, (August).

Lian, S., \& Tam, C. L. (2017). Work Stress , Coping Strategies and Resilience: A Study among Working Females, 10(12), 4152.

https://doi.org/10.5539/ass.v10n $12 \mathrm{p} 41$

Lucas, N., Shipley, M., Mathews, R., Berry, H., Rodgers, B., \& Davies, A. (2011). Parent and child wellbeing and the influence of work and family arrangements: a three cohort study.

Milnes, B. (2016). Families and Whānau Status Report 2015, 150. Retrieved from http://www.superu.govt.nz/sites/ default/files/Families and
Whanau status report.pdf

Nies, M. A., \& Mcewen, M. (2014). Community / Public Health Nursing Promoting the Health of Populations 6th edition. Elsevier Health Sciences.

Oakley, K. (2008). Occupational Health Nursing (3rd ed). England: John Wiley \& Sons, Ltd.

Oktaviana, R. (2015). Hubungan Antara Subjective Well-Being dengan Self Management Pada Ibu Bekerja di Rumah Sakit Muhammadiyah Palembang, 107-116.

Ora, C. D., Ball, J., Recio-saucedo, A., \& Griffiths, P. (2016). Characteristics of shift work and their impact on employee performance and wellbeing: A literature review. International Journal of Nursing Studies, 57, $12-27$.

https://doi.org/10.1016/j.ijnurstu. 2016.01.007

Ora L. Strickland, C. D. (2001). Measurement of Nursing Outcomes Second Edition Volume 2: Client Outcomes and Quality of Care (Vol. 92). Springer Publishing Company, Inc.

Robertson, Ivan; Cooper, C. (2011). Well-Being: Productivity and Happiness at Work. London: Palgrave Macmillan.

Ruppanner, L. (2011). Conflict

Vura Medika | VOLUME 11/NOMOR 02/MARET/2019 
Between Work and Family: An Investigation of Four Policy Measures. Social Indicators Research, https://doi.org/10.1007/s11205011-9933-3

Ryff, C. D. (2014). Psychological Well-Being Revisited : Advances in the Science and Practice of Eudaimonia, 53706, 10-28.

https://doi.org/10.1159/0003532 63

Sabra, H. E., \& Morsy, S. M. (2016). Occupational Health Hazards among Nurses at Quena University Hospital, 5(3), 28-34. https://doi.org/10.9790/19590503042834

Saryono. (2011). Metodologi Penelitian Keperawatan. Purwokerto: Unsoed.

Sharma, J., Dhar, R. L., \& Tyagi, A. (2015). Stress as a mediator between work - family con fl ict and psychological health among the nursing staff: Moderating role of emotional intelligence. Applied Nursing Research. https://doi.org/10.1016/j.apnr.20 15.01.010

Sugiyono. (2011). Metode Penelitian Kuantitatif, Kualitatif, dan $R \&$ $D$. Alfabeta,cv.

Sugiyono. (2013). Metode Penelitian Pendidikan Pendekatan

Kuantitatif, Kualitatif, dan $R \& D$. Bandung: Alfabeta.
Survey Angkatan Kerja Nasional (Sakernas). (2016). Penduduk Usia 15 tahun ke Atas menurut Jam Kerja Utama dan Lapangan Pekerjaan Utama Industri (dalam ribuan).

Westrupp, E. M., Martin, A., \& Zubrick, S. R. (2016). Maternal Work - Family Conflict and Psychological Distress: Reciprocal Relationships Over 8 Years, 78(2), 107-126. https://doi.org/10.1111/jomf.122 62

Widyasrini, J. (2016). Konflik Peran Ganda, Coping Stress dan Dukungan Sosial sebagai Prediktor. Universitas Muhammdiyah Surakarta.

Zheng, C., Kashi, K., Fan, D., Molineux, J., \& Ee, M. S. (2016). Impact of individual coping strategies and organisational work-life balance programmes on Australian employee well-being. International Journal of Human Resource Management, 27(5), 501-526.

https://doi.org/10.1080/0958519 2.2015.1020447 